\title{
An Ample Study of Numerous Intelligent Systems used for Agriculture: Review
}

\author{
Amish Patel \\ Assistant Professor \\ Uka Tarsadia University
}

\author{
Puja Kadam \\ Assistant Professor \\ Uka Tarsadia University
}

\begin{abstract}
Agriculture in India has a very significant history. Today, India ranked second worldwide in terms of farm output. Over the year agriculture has contributed towards India's GDP but is narrowly declining with the country's economic growth due lack of initiatives. This paper presents a review on different types of intelligent systems used for agriculture in India namely expert systems using fuzzy logic, types of robotics which increases the precision and exactness for cultivation of crops, seed plantation techniques and atomization of water and soil in agriculture. All these systems are used in order to improve the per capita income as well as decreasing human efforts by automating the agriculture.
\end{abstract}

\section{Keywords}

Intelligent Systems, Fuzzy Logic, Robotics, Plantation

Technique, Water, Soil

\section{INTRODUCTION}

For around $80 \%$ Indian population, agriculture is one of the major source of livelihood. It has also always been India's most important economic sector. [19]Although crop production is not up to the mark anywhere in the world but in developing countries like India it is even lower in comparison to other countries. To improve the production and it's quality numerous intelligent systems can be adapted. [7]All the systems were identified as a powerful tool with expensive potential in agriculture. It include expert systems which defines it as "a computer program designed to model the problem solving ability of a human expert" , Fuzzy expert systems which are being used in agriculture for various activities i.e soil preparation, seed selection, pesticide management, water scheduling, weed management etc, with an objective to get better results and good yield out of crops and robotics that can perform agricultural procedures alone such as spraying and motorized weed control, fruit selection, inspecting the farms day \& night for an efficient result [8]

\subsection{Robotics in Agriculture:}

A conventional or traditional technique for farming depends upon humans for lifting, dragging and weeding. Humans are forced to work in all conditions under risk; whereas Robots can work impatiently in all conditions; all you have to do is put a program to execute the desired actions. Robot will stroll on fields to take care for crops for their appropriate growth. There are different types of Robots that can be used in agriculture and now Indian agriculture system had started adopting it. In [5] robots are of following types:

\subsection{Demeter}

Demeter is a Robot farmer which is able to drive itself without the human interventions. The robot is named after the Roman goddess of agriculture. Humans get tired of harvesting but on the other side Demeter can harvest crops like wheat and alfalfa ; also it does not get exhausted.

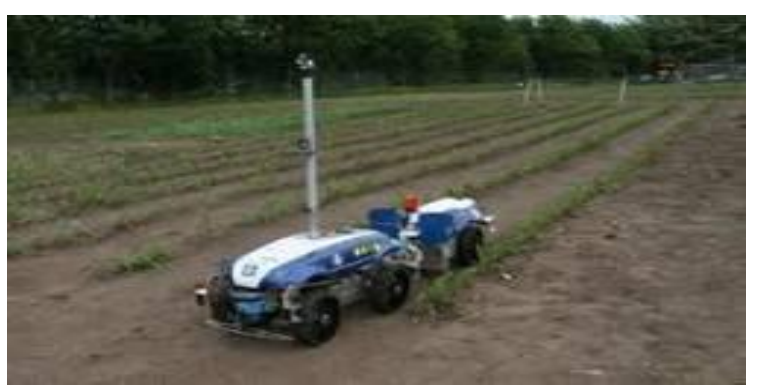

Fig 1. Demeter [5]

\subsection{Weed Controller}

The invention of new weeding technologies can lessen human effort by $50 \%$ to $100 \%$ in organically cultivated sugar beets and vegetable and also use of herbicide by 75 to $100 \%$ in high value crops. The duty of the weed removing machine is to get rid of or wipe out the weed. Crops that are developed in rows can be weeded by operating a dig over in between the crop rows.[14]

\section{Advantages:}

It could reduce farmer's money. For harmless night work, field obstacles can be planned into every field map so the tractor can involuntarily take prevention action.

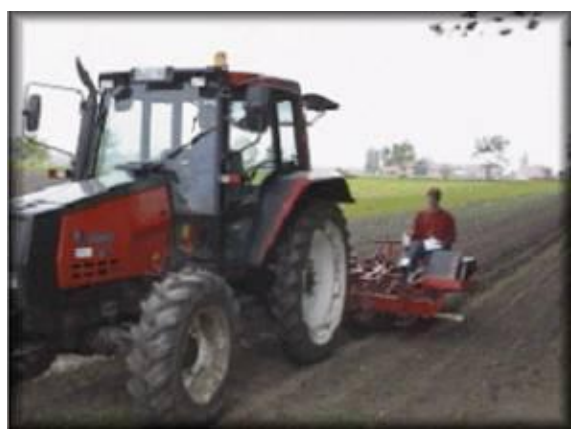

Fig 2. Weed Controller [5]

\subsection{Robots used in Forests}

This type of robot is used for cutting up of wood, nurture trees, and pruning of Christmas tree and for harvesting tissue and hard wood in the forests. It occupies a special jaws and axes for cutting the branch. The forester robot having six legs moves wonders in the forest.

\subsection{Fruit picking robot}

It was been developed in [5] the beginning of 1980's. Initially the robots required picking ripe fruit without destructing the leaves or branches of the tree. The camera is installed on the 
arm of the robot and the colors recognized are judged against with properties accumulated in the memory. If a match occurs, the fruit is picked. It has 5 degrees of freedom to move around in all the ways. If a fruit is surrounded by leaves, an air jet can be used to propel the leaves. The force applied is enough to pick the fruits ; it cannot squeeze the fruit[14].

\section{Advantages}

Proficient in harvesting citrus fruits and apples.

\section{Limitations}

Incapability of picking the fruits if surrounded by branches.

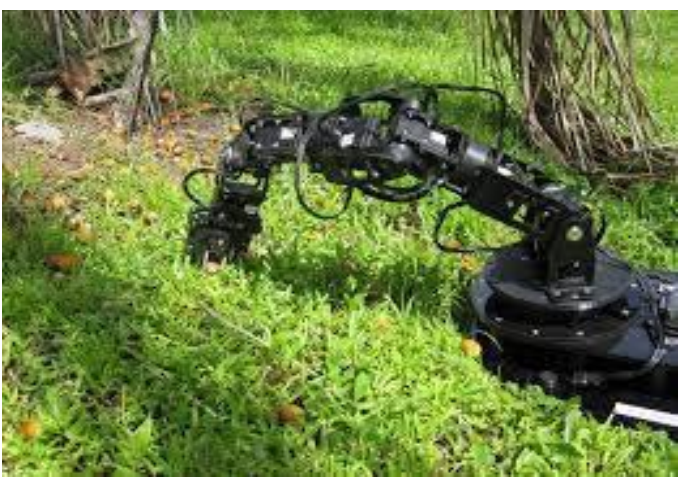

Fig 3. Fruit Picking Robot [5]

\section{SEED PLANTATION TECHNIQUE}

It is an innovative machine to automate the process of sowing crops such as sunflower, baby corn, groundnut and vegetables like beans, lady's finger, pumpkin and pulses like black gram, green gram etc. in order to reduce the human effort and increase the yield. DC motor is used to automatically plant seeds. The distance between the two seeds are controlled and varied by using Microcontroller. Different distances are used to cultivate different seeds. The whole process is controlled by Microcontroller and can be used when the robot reaches the end of the field by changing the direction with the help of remote switches [13].

The seed plantation technique machine contains following components:

1. Digitizer - The output of the sensor may or may not be compatible with the controller. Hence it becomes necessary

2. to convert the pulse in the form which controller can accept.

3. Microcontroller - It is the heart of our system. It is the main control block and all other blocks are interfaced to the Controller.

4. Relay Driver: IC ULN 2003 is relay diver is used for to drive relay.

5. Relay: Relay is used as a switch to control the final process \& also to set the alarms. We are using a sugar cube type relay, which is easily available.

6. Display: Here we are using LCD type display; LCD display is display of welcome message of project and seeding counter.

7. Sensor: It is the most important elements of this system. We are using proximity sensor (metal detect) that sense complete rotation of wheel. And second and third sensor is used LDR type. That sense is seed storage and when seed drop pipe is block. After detecting the object, the sensor sends a pulse to the micro controller [12].

Advantages: Using this technique, if we sow the seeds the distance between the seeds will be fixed, time consumption and wastage of seed and man power will be used at minimal.

\section{ATOMIZATION OF WATER AND SOIL}

Atomizing is the essential part of agriculture. If it is installed and operated properly will help us to save lots of money and conserve water upto a greater extent. [10]Using 8051 microcontroller and GSM this technique is used to atomize the irrigation system for proper welfare of the society by enhancing perfect irrigation in particular area.

To begin with we first need to continuously monitor the moisture of the soil for which we are using soil sensors based on the principle of parallel capacitor. It is used to determine the soil moisture by measuring the dielectric constant of the soil. The default values are stored in the database EEPROM , where the values received using soil sensors and that stored in database area compared which ensures faithful irrigation for particular crop[20].

Secondly, we monitor the water level of the well, is used to ensure that the water level has not reached the critical point and still the motor is not running on. If we want to know about the water level, we can send the message to the central unit and it will check and reply the status. The receiver uses a standard form of message decoding called NMEA protocol. In our project, we do not display the message on LCD although we have the facility.

Water level sensor is used to check the level of the water which is implemented using electromagnetic reed switch and a floating magnet. The reed switch is based on the principle that when it will come in contact of any magnetic field it provides conductivity[14].

Here LCD and GSM receive the information about temperature, humidity and conditions of

the soil and motor. Water level sensor sends the information to the microcontroller which in return sends the information to relay then switch off/on the motor.

Advantages: Water wastage is not done. Exact field condition can be known to the farmers by sending SMS consuming less time.

\section{FUZZY EXPERT SYSTEM}

\subsection{Water Irrigation Expert System}

The founder of the water irrigation expert system is A. Eddahhak1. These system is largely used in Egypt as it faces the scarcity of water. A "fuzzy controller" expert system has been developed and used to monitor drip irrigation duration to reduce water using as variables soil moisture degree and air temperature in greenhouse". [6]Here the moisture of the soil and drip irrigation system is measured using electronic circuits; based on the moisture the water is fed to crop to help it irrigate.

Another fuzzy expert system was developed to estimate the amount of water to take-up for irrigation, environmental conditions of soil type, and this was performed using Mamedani controller and it was built using Matlab software. 
Limitation:

- Water logging.

- Salinity and alkalinity of land.

- $\quad$ Ill aeration of soil.

- Pollution of underground water.

Success Rate:

The field water efficiency of drip irrigation is typically in the range of 80 to 90 percent when managed correctly.

Advantages:

- Increase of food production.

- Modify soil or climate environment - leaching.

- Lessen risk of catastrophic damage caused by drought.

- Increase income \& national cash flow.

- Increase labor employment.

- Increase standard of living.

- Increase value of land.

- National security thus self sufficiency.

- Improve communication and navigation facilities.

- Domestic and industrial water supply.

- Improve ground water storage.

- Generation of hydro-electric power[18].

\subsection{Climate control expert system}

Here in [6]various climatic parameters are regulated using LabVIEW software, and according the climate is controlled by cooling and heating ensuring the required range of temperature and humidity.

\subsection{Fertilizer Management Expert System}

This system in [6] was developed for recommending the fertilizer for crop cultivation. It takes the value of phosphorous, nitrogen, potassium and correspondingly calculate the soil nutrients required.

\subsection{Pest control and Diagnosis Expert Systems}

FuzzyPest was developed in order to forecast the pest activity level by which we will be able to determine the damages done by the pest. Here the information is provided to farmers though the internet by using FuzzyPest [6]. This system has been verified by Malaysia Agriculture Research \& development Institute, Malaysia

SOYPEST was developed to solve pest related problems of farmers by providing diagnosis and preventive measures against it. The objective behind this system is to support decision making that farmers take for crop cultivation. It is being widely used for growing crops in different regions of India.

\subsection{Insect Pest Management in Groundnut crop}

In [11] system is able to identify various symptoms, identify actual insect pest and then accordingly recommend various control measures as per knowledge base. This expert system provides remedial measures for disease management of Ragi food crop of Karnataka state of India.

\subsection{Disease diagnostic expert system}

A disease diagnostic system was developed particularly for oilseeds like soya bean, groundnut

rapeseeds etc which will helps to increase the ability of the cultivators/extension workers researchers in

decision making. It is basically a web-based intelligent disease diagnosis system (WIDDS) using the fuzzy logic approach , thus this system will help in diagnosis approach in agriculture.

Various expert systems were developed as follows:

a) POMME is an Expert system for Apple Pest Orchard Management. It was developed in Virginia to help in managingdiseases and insect-pests on apples.

b) EGES is a multilingual expert system for the diagnosis of pests, disease and nutritional disorder of six green housevegetable viz., pepper, lettuce, cucumber, bean, tomato, and aborigine.

c) CPEST is an expert system for managing pests and diseases of coffee in a developing country.

d) AMRAPALIKA is an Expert System for the diagnosis of pests, diseases, and disorders in Indian Mango. The system makes diagnosis on the basis of response/responses of the user made against queries related to particular disease symptoms.

e) POMI is an Expert System for integrated pest management of apple orchards. This system was developed cooperatively at the Istituto per la Ricerca Scientifica e Technologica and the Istituto Agrario S. Michele in Italy.

\subsection{Rice Expert System}

In India, Sarma developed an expert system in order to diagnose and manage the diseases occurring in rice crop. It was developed to diagnose and manage the diseases occurring in rice crop. It is a computer program composed of knowledge base, inference engine and user interface. The system also contains an image database which is also integrated with the system for making decision support more interactive. The pictures related to the disease symptoms are stored in the picture database and intelligent system modules it with the interface using rule based system and decision making algorithms.

\section{Success Rate:}

Rice output in India hit a new record at 95.3 million tonnes, a $7 \%$ increase from the year 2014.

\subsection{Tomato expert system}

A web based tomato crop expert information system was developed by Babu [2] in India. This expert system basically contains two parts i.e. tomato information system and tomato crop expert system. Here the user can get all the static information regarding various species, their diseases, 
symptoms, preventions and chemical controls. The user can have an interaction with the expert online. Experts ask questions to the user and according to the responses given by the user the expert system specifies the diseases or pest and its control measures to be taken. The system uses rule based system, knowledge base, optimization algorithms to respond to the queries of the user[17]

\section{Success Rate:}

Indian agriculture accomplished an all-time record production of 85.9 million tones of tomato, a $6.4 \%$ increase.

\subsection{Rapeseed Mustard Expert System}

In [1] developed an image based Rapeseed Mustard disease expert system in India. Numerous disease like white rot, downy mildew complex, white rust Alternaria bright diseases were diagnosed and control measures were taken to cure it. System is designed of components like a user interface, knowledge base, a database and an inference mechanism. The system includes problem selection, knowledge acquisition, knowledge representation, programming, testing and evaluation.

\section{Success Rate:}

Alternaria blight range from $5-15 \%$ and can reach $47 \%$. White rust in B. juncea can result in yield losses of up to $47 \%$ , Rot of mustard has become important in recent times in India and elsewhere with high disease incidence and causes up to 40 $\%$ yield losses leading to discouragement of growers of the crop.

\subsection{Mango Expert System:}

Prasad in [2]developed an expert system called AMARPALIKA for diagnosing 14 different pests including eight diseases and six insects in Indian mango varieties. Even though India is the biggest producer of Mango but still the per captia production is low and it has been proved that $20-25 \%$ of it is degraded due to the spoilage of the fruit at post harvest stages. The knowledge base of the system contains knowledge about symptoms and remedies of 14 pests of Indian mango tree appearing during fruiting season and non-fruiting season. [11] The picture based on the system contains pictures related to symptoms and are displayed along with the query of the system.

\section{Success Rate:}

The expert system has been preliminarily tested in North and North-central India by a team of researchers and scientists who observed that on an average $100-300$, i.e. $20-50 \mathrm{Kg}$, more fruits per plant are obtained by using the crop protection and pest management schemes prescribed by the expert system.

\section{NECESSITATE OF EXPERT SYSTEMS IN AGRICULTURE:}

The requirement of expert systems for agriculture is identified by analyzing the problem that occurs while using the traditional system for cultivating the crops. Following problems are faced by the traditional farmers while cultivation[15].

a. Stagnant Information: Investigating the information stored and available in the agriculture domain discovered that this information is static and it won't help the farmers to grow more.

b. Specialties Integration: Problems like plant pathology, entomology, nutrition or any other cannot be handled properly, these problems may be due to numerous causes and should be taken care of by integrating the knowledge behind the information.

c. Combination of more than one information source: Sometimes an experts may be required to combine factors so that accurate diagnosis can be made and the same can be treated as well.

d. Updating: If any changes appears in chemical or their dosages, it's impact on the environment should be considered. But updating this information in documents, audio tapes or video tapes may require longer period of time.

e. Information Unavailability: Information is available only from human experts and not available through any media. This information must be transferred to the farmers which would ultimately help them to improve the agriculture aspects[16].

\section{ADVANTAGES AND LIMITATIONS OF EXPERT SYSTEMS}

Advantages:

1. The systems can be used by the farmers, researchers, personnel to identify the crop disease.

2. User can identify the disease based on the photographs.

3. Maintain noteworthy levels of information.

4. Reduce employee training costs.

5. Reduce time to greater extent to make decisions and solve problems.

6. Human errors can be reduced.

Limitations:

1. Many farmers are illiterate in the country, and knowledge of computer is still not reachable at rural areas.

2. If new disease is identified it should be included in the knowledge base.

3. Lots of farmers are not competent with English, so such systems should be developed in regional languages.

4. The picture quality should be improved, as on the basis of the picture only experts can identify the disease and recommends preventive measure. But it picture is not identified properly, it might result in the degradation of the crop more compared to previous.

5. Maintenance and extensions of rule based is difficult to add on if a very large system is there.

\section{CONCLUSION}

From the above facts and figures and also from the study of different intelligent systems it can be concluded that for better vegetative growth and irrigation purpose we can use expert systems comprising of different robotics too. The use of these techniques will help us to optimize the profit

and the productivity of vegetation. Initially one has to invest a little bit in order to achieve the best quality of production but once it is done it will be a long-term benefit. 


\section{REFERENCES}

[1] Vinod Kumar, Sushma Lehri, Ashok Kumar Sharma, P.D.Meena and Arvind Kumar, 2008 , "Image Based Rapeseed-Mustard Disease Expert System : An Effective Extension Tool,” Indian Res. J. Ext. Edu. 8 (2\&3).

[2] Prasad, R., Ranjan, K. R., and Sinha, A. K., 2006, “ AMRAPALIKA: An expert system for the diagnosis of pests, diseases, disorders in Indian mango," Knowl.Based Syst. 19 vol. 1, pp. no 9-21.

[3] Babu, M. S. P., Murty, N. V. R., and Narayana, S. V. N. L., 2010, "A web based tomato crop expert information system based on artificial intelligence and machine learning algorithms," International Journal of Computer Science and Information Technologies 1 vol.1 pp.no 615.

[4] Sarma, S. K., Singh, K. R., and Singh, A., 2010," An Expert System for diagnosis of diseases in Rice Plant," International Journal of Artificial Intelligence 1 vol. 1, pp.no 1-6.

[5] Shwetal, V.P. Bhope, "A Review On Agricultural Robots", International Journal of Advanced Research in Computer Engineering \& Technology, 7 vol.4, pp. no3089-3093.

[6] Harsimranjit Singh, N. Sharma, "A Review of Fuzzy Based Expert System in Agriculture", International Journal of Engineering Sciences \& Research Technology, 3 vol. 7, pp.no 912-915

[7] L. Pradhan, B. B. Mohapatra," E-agriculture: A Golden Opportunity for Indian Farmers", International Journal of Research and Development,1, vol. 4, pp.no 64-68

[8] Sumitha Thankachan, Dr.S.Kirubakaran, "An Intelligence Based Alert System for Farmers", International Journal of Innovative Research in Computer and Communication Engineering, 3, vol. 2, pp.mo. $150-158$

[9] Er. Ramanjeet Kaur," Importance of Expert Systems used in Agriculture: A Review", International Journal of Enhanced Research in Science Technology \& Engineering, 5, vol. 3, pp.no.265-269.

[10] Ahmed Rafea, "Expert System Applications: Agriculture", Central Laboratory for Agricultural Expert Systems.
[11] P. Mercy Nesa Rani, T. Rajesh and R. Saravanan," Expert Systems in Agriculture: A Review", International Journal of Computer Science and Applications, vol.3, pp.no. 59-71.

[12] Howard W. Beck, Pierce Jones and J.W. Jones(1989)," SOYBUG:An expert system for soyabean insect pest management", Agricultural Systems, URLhttp://www.sciencedirect.com/science/article/pii 1989, Vol. 30, Issue, pp.269-286.

[13] 13. M.Ramu, CH.Rajendra Prasad," Cost effective atomization of Indian agricultural system using 8051 microcontroller", International Journal of Advanced Research in Computer and Communication Engineering, 7, vol. 2, pp.no. 2563-2566.

[14] R. Fitch, S. Sukkarieh.” Robotics and intelligent systems for large scale agriculture", Australian Centre for Field Robotics, School of Aerospace, Mechanical and Mechatronic Engineering,

[15] P. Chakraborty, D.K. Chakrabarti ," An Example of Agricultural Expert Systems Being Used in India", Georgian Electronic Scientific Journal: Computer Science and Telecommunications,1, vol. 5, pp.no 10-12.

[16] S. Thankachan, Dr.S.Kirubakaran,, "An Intelligence Based Alert System for Farmers", International Journal of Innovative Research in Computeand Communication Engineering, 3, vol. 2, pp.no. 150-158.

[17] Savita Kolhe, G K Gupta, "Intelligent Systems for Agriculture Domain”, International Journal of Computer Applications, pp.no. 14-18.

[18] Wharton, P. S., Kirk, W. W., Baker, K. M. and Duynslager, L. 2008. A web-based interactive system for risk management of potato late blight in Michigan. Computers and Electronics in Agriculture, 61, 136-148.

[19] Kolhe, Savita, Kamal, Raj, Saini, Harvinder S. and Gupta, G. K. 2009. A fuzzy-logic based on-line disease diagnosis system for soybean. A fuzzy-logic based online disease diagnosis system for soybean. Soybean Research, 7, 73-81.

[20] P. Thomas, Bhoomi, Gyan Ganga, egovernance and the Right to Information: ICTs and Development in India, Telematics and Informatics, vol.26, pp. 20-31, 2009. 